\title{
Management of Rhodococcus equi pneumonia in foals
}

This article was published in the following Dove Press journal:

Veterinary Medicine: Research and Reports

26 November 2013

Number of times this article has been viewed

\section{Imogen Johns}

Department of Clinical Sciences and Services, Royal Veterinary College, North Mymms, UK
Correspondence: Imogen Johns Department of Clinical Sciences and Services, Royal Veterinary College, Hawkshead Lane, North Mymms, Hertfordshire AL9 7TA, UK Email ijohns@rvc.ac.uk
Abstract: Rhodococcus equi, a gram-positive facultative intracellular bacterial pathogen, is the most important cause of pneumonia in foals aged 3 weeks to 5 months. The disease occurs worldwide, resulting in significant morbidity and mortality on endemically affected farms. Foals appear to become infected early in life, but clinical signs are typically delayed until 1-3 months of age because of the insidious nature of the disease. Although pneumonia is the most common clinical manifestation, up to $74 \%$ of foals may concurrently have extrapulmonary disorders, including both extrapulmonary infections (abdominal abscessation, colitis, osteomyelitis) and immune-mediated disorders (nonseptic synovitis, uveitis). Diagnosis is based on the combination of clinical signs and abnormalities on hematologic screening and thoracic imaging in an appropriately aged foal and is confirmed by bacteriologic culture of the organism. Management of $R$. equi infections, in particular on farms with endemic disease, combines appropriate treatment of affected foals with preventative measures targeted at preventing infection and identifying foals before the development of severe disease. The combination of rifampin and a macrolide antimicrobial is recommended for treatment, as the combination is synergistic, reaches high intracellular concentrations, and should minimize the development of antimicrobial resistance. The prognosis for survival for foals with $R$. equi pneumonia is good, especially in foals mildly or subclinically affected, as is the prognosis for future athletic performance. Screening for early identification before the development of clinical signs has been advocated on endemically affected farms, although the most appropriate method, the timing of screening, and the selection of foals requiring treatment have yet to be determined. Recent evidence suggests that a high proportion of foals identified via screening methods such as ultrasonographic evaluation of the thorax can recover without treatment, questioning the "trigger" required for treatment of identified cases.

Keywords: extrapulmonary disorder, infection, rifampin, antimicrobial, immunity, inhalation, virulence

\section{Introduction}

Rhodococcus equi, a gram-positive facultative intracellular bacterial pathogen, is the most important cause of pneumonia in foals aged 3 weeks to 5 months. ${ }^{1,2}$ The disease occurs worldwide, resulting in significant morbidity and mortality on endemically affected farms. ${ }^{1-7}$ During the last several decades, our understanding of the pathogenesis, virulence, immunity, and treatment of $R$. equi pneumonia has advanced significantly, resulting in improved survival rates and preventative strategies. Despite these advancements, an effective vaccine has yet to be developed, and newer challenges, including the emergence of antimicrobial-resistant $R$. equi and effective management of subclinically affected foals, have been identified. ${ }^{3,4,8-10}$ 


\section{Pathogenesis and virulence}

The primary route of pulmonary infection is via inhalation, with ingestion of the organism as a secondary route of exposure. Although the age at which clinical signs develop in foals varies between studies, from 36-97 days, infection is believed to occur very early in life, as early as the first day or two. ${ }^{3,411-14}$ After inhalation, the bacteria fix complement on their surface, and on interaction with macrophages, stimulate phagocytosis via a receptor-mediated process. ${ }^{15}$ The virulence of $R$. equi relies on the ability of the organism to replicate in macrophages, which is dependent on its capacity to interfere with endosomal maturation after phagocytosis and to prevent acidification of the vacuole in which it resides. ${ }^{16-19}$ Eventually, intracellular proliferation of the pathogen leads to the necrotic death of the macrophage, with massive damage to lung tissue, resulting in the classic abscess formation. Not all strains of $R$. equi can cause disease, and those that are avirulent lack the capacity to effectively multiply within macrophages. ${ }^{20}$ Virulent strains consistently contain a 15-17-kDa protein, called VapA, which is encoded by the virulence plasmid. This plasmid enables intracellular replication in macrophages by preventing maturation of the phagosome to the stage of vacuoles containing $R$. equi with lysosomes. ${ }^{21}$ Other virulence-associated proteins have been identified; however, they do not appear to be critical in the development of disease. ${ }^{22}$

\section{Immune response}

In contrast to foals, immunocompetent adult horses are immune to infection and are thus used as a model for the "immune" phenotype for R. equi infection.

\section{Cell-mediated immunity}

Immunity to $R$. equi appears to rely on the presence of both specific antibodies and an efficient cell-mediated response, although the nature of this response, and why some foals are unable to clear the organism effectively, remains to be determined. ${ }^{23-26}$ Clearance of the organism after experimental bronchial inoculation in adult horses relies on the induction of a type 1, Thelper (Th) 1 response, which involves production of antigen specific Th1 lymphocytes to clear intracellular R. equi via production of interferon gamma (IFN $\gamma$ ) and macrophage activation, as well as production of antigenic specific cytotoxic $\mathrm{T}$ lymphocytes, which function to recognize and kill R. equi-infected cells. ${ }^{1}$ A lymphoproliferative response, characterized by increased numbers of CD4+ and CD8+ T lymphocytes as well as $R$. equi cytotoxic T lymphocytes (CTL) subsets, is seen in bronchoalveolar lavage fluid collected from horses after challenge. ${ }^{27,28}$ In mice, pulmonary clearance of R. equi requires functional T lymphocytes. ${ }^{24-26}$ Both CD4+ and CD8+ T lymphocytes contribute to host defence against R. equi, but CD4+ lymphocytes play the major role and are absolutely required for complete pulmonary clearance of the bacteria. CD4+ and CD8+ cells secrete IFN $\gamma$, which activates macrophages, the host cells of $R$. equi. ${ }^{29}$ A cytokine profile dominated by IFN $\gamma$ production results, as well as production of $R$. equi-specific immunoglobulin (Ig)Ga and IgGb. ${ }^{29,30}$ Macrophages that have been activated by IFN $\gamma$ produce both reactive oxygen and reactive nitrogen intermediates, combining to form peroxynitrate, which efficiently kills $R$. equi. ${ }^{18}$

Although CD4+ $\mathrm{T}$ lymphocytes are essential for clearance of the organism, the role of CD8+ CTL has recently been highlighted..$^{27,31}$ Patton et al determined that adult horses have R. equi-specific CTL in both peripheral blood and within the lung, which function to recognize and kill $R$. equi-infected cells. $^{27}$

\section{Antibody-mediated immunity}

Although the cell-mediated immune response is dominant in clearance of $R$. equi, humoral immunity is also involved. Adult horses challenged with the organism have a significantly increased IgG, but not IgM, response, which is consistent with a protective recall response. ${ }^{32}$ Opsonization with R. equi-specific antibody increases the level of phagosomelysosome fusion and significantly enhances the killing of $R$. equi by alveolar macrophages in foals. ${ }^{33}$

\section{Immune response in foals}

An inability to mount an effective Th1 immune response has been suggested as the reason for foals' susceptibility to $R$. equi. ${ }^{34}$ Evidence to support this has included studies showing that newborn foals exhibit a marked inability to express the $I F N \gamma$ gene and produce IFN $\gamma$ protein, ${ }^{34}$ although a subsequent study indicated that in fact, foals are capable of producing IFN $\gamma$, but $R$. equi-infected foals have significantly reduced proliferative responses to $R$. equi antigens compared with adult horses. ${ }^{35}$ An age-associated deficiency in $R$. equi-specific CTL has also been identified, with 3-week-old foals having a significantly lower activity of CTL in both peripheral blood and bronchoalveolar lavage fluid ${ }^{27}$ However, more recently, accelerated development of $R$. equi-specific CTL was demonstrated in foals after oral inoculation with virulent $R$. equi. ${ }^{36}$ Thus, although an ability to mount an effective and protective Th1-type response was believed to explain the unique susceptibility of young foals to infection with $R$. equi, recent studies have shown that 
with an appropriate challenge, foals can produce IFN $\gamma$ and a specific antibody and can develop $R$. equi-specific cytotoxic T lymphocytes. ${ }^{35,36}$ This evidence, along with the apparent high rate of spontaneous resolution in foals with subclinical disease, suggests there is unlikely to be a "blanket" explanation based on a deficient immune response present in all foals, and a more cohesive explanation is likely to be multifactorial and multifaceted..$^{3,4,10}$

\section{Clinical signs}

The most frequently recognized clinical manifestation of infection caused by $R$. equi is pyogranulomatous bronchopneumonia and pulmonary abscessation in foals aged 3 weeks to 5 months. ${ }^{1,2,37}$ In most cases, the development of clinical signs of pneumonia is chronic and insidious, with initial signs including a cough, fever, and lethargy. As the pulmonary pathology progresses, increased respiratory rate and effort, tachycardia, and anorexia with loss of condition can occur. ${ }^{38}$ In a small proportion of foals, severe clinical signs of respiratory distress develop rapidly, in some cases with minimal preexisting respiratory signs. This form is thought to be a manifestation of acute lung injury/acute respiratory distress syndrome and has been associated with a relatively poor prognosis, despite intensive therapy. ${ }^{39,40}$

\section{Extrapulmonary disorders}

A proportion of foals with $R$. equi pneumonia will concurrently develop extrapulmonary disorders (EPD). ${ }^{41,42}$ Extrapulmonary manifestations of $R$. equi infection appear to occur commonly, with $74 \%$ of foals affected in one study. ${ }^{41}$ These disorders can develop as either infection in sites distant to the lungs, such as septic arthritis and osteomyelitis, abdominal abscessation, or colitis, or as a consequence of an immune-mediated reaction. Uveitis, nonseptic synovitis (typically of multiple joints), and hemolytic anemia are reported immune-mediated infections. The clinical signs of the EPD will depend on the body system affected, as will the treatment protocol. In cases of infectious EPD, antimicrobials targeted at the pulmonary infection will tend to be appropriate, although local therapy, such as synovial lavage, should be considered in cases with septic synovitis. Foals with nonseptic synovitis, characterized by nonpainful effusion of multiple joints, typically do not require specific treatment, with effusion resolving as the pulmonary infection resolves. In contrast, foals with uveitis and immune-mediated hemolytic anemia (IMHA) will typically require specific treatment of these disorders. Topical corticosteroids and atropine, as well as systemic nonsteroidal anti-inflammatory drugs, are appropriate for the treatment of foals with uveitis. Although corticosteroids are the mainstay of treatment of horses with IMHA, their use in horses with severe bacterial infections may interfere with the immune response to clear the infection, as steroid treatment diminishes the lysosomal enzyme and oxygen radical release from polymorphonuclear leukocytes and depresses intracellular killing of bacteria. ${ }^{43,44}$ However, the IMHA in foals with $R$. equi may be sufficiently severe that systemic corticosteroids are indicated, in addition to packed red cell/ whole blood transfusions. ${ }^{42}$

Although the presence of EPD appears to be a relatively common occurrence in foals with $R$. equi infections, their presence can complicate and prolong treatment and is associated with a poorer prognosis, with $43 \%$ survival in one study of foals with EPD compared with $82 \%$ survival in foals without EPD. ${ }^{41,42}$

\section{Diagnostics Identification of the organism}

Although identification of clinical signs consistent with pneumonia in an appropriately aged foal housed on a farm with a history of $R$. equi infections is commonly used to make a diagnosis of $R$. equi pneumonia, definitive diagnosis requires identification of the organism from an infected site (tracheobronchial aspirate in foals with pneumonia, or other site in foals with EPD) in conjunction with evidence of septic inflammation and consistent clinical signs. ${ }^{1}$ Bacteriologic culture allows for identification of possible concurrent bacterial infection, as well as permitting antimicrobial sensitivity testing. Mixed infections with a wide variety of gram-positive and gram-negative bacteria have been reported in foals with $R$. equi pneumonia, highlighting the importance of sensitivity testing, especially in foals with concurrent gram-negative infections resulting from the relatively limited action of routinely used antimicrobials against gram-negative pathogens. ${ }^{38,45,46}$ The need for sensitivity testing of $R$. equi isolates has become increasingly important, with increased rates of resistance to both rifampin and macrolides reported in recent years, in particular when antimicrobial prophylaxis has been used. ${ }^{8,9}$ Amplification of the vapA gene via polymerase chain reaction has been shown in several studies to be more sensitive than bacterial culture, but has the disadvantages of allowing neither for culture of concurrent pathogens nor for sensitivity testing of isolates. ${ }^{47}$ In addition, small numbers of bacteria can be detected, which may result in a higher incidence of false-positive results secondary to environmental contamination. As such, polymerase chain 
reaction is not recommended as the sole method by which to identify $R$. equi. ${ }^{1}$

\section{Imaging}

Both radiography and ultrasound can be used to image pulmonary lesions and can be useful tools in assessing the severity of disease and the response to therapy. Ultrasound tends to be used more routinely, in particular in nonhospitalized foals, because of its ease of use and wide availability. Although ultrasound will only detect lesions on the peripheral lung surface, and will thus fail to identify lesions within the pulmonary parenchyma that are deep to normally aerated lung, the method appears to perform adequately when compared with radiography. In some instances, such as when identifying pleural effusion and small pleural lesions, it may be more sensitive. ${ }^{2,48}$ In one study of foals with $R$. equi pneumonia in which both radiographic and ultrasonographic evaluations were performed, radiographic lesions were visible ultrasonographically in 16 of 17 foals. ${ }^{48}$ Radiographic abnormalities most commonly identified in foals with $R$. equi pneumonia include single or multiple nodular or cavitary lesions (abscesses), an alveolar or interstitial pattern, and tracheobronchial lymphadenopathy. ${ }^{12,49}$ Although $R$. equi is not the only cause of pulmonary abscesses in foals, their presence had a specificity of $85 \%$ in one study of 113 foals with bacterial pneumonia. ${ }^{38}$

Pulmonary abscesses can be similarly identified via ultrasound, characterized as well-defined, hypoechoic nodules without evidence of normal pulmonary architecture such as small airways or vessels within the central region. Consolidated lung tends to have a less well-defined margin and also will be hypoechoic relative to the surrounding lung parenchyma, but in contrast to an abscess, it will retain elements of the normal lung architecture such as bronchi (linear hyperechoic foci) and vessels. Pleural effusion is rarely identified in foals with $R$. equi pneumonia, but even small amounts of fluid can be readily identified as an accumulation of anechoic material between the visceral and parietal pleura. ${ }^{48}$

\section{Hematology and acute phase proteins}

Although a neutrophilic leukocytosis, hyperfibrinogenemia, and hyperglobulinemia are commonly seen in foals with $R$. equi infections, they are specific neither for the bacterial species nor for the body system affected..$^{1,14,38}$ Used with other diagnostic abnormalities such as the presence of clinical signs of pneumonia and pulmonary abscessation, an increased white cell count and fibrinogen concentration may increase the index of suspicion for $R$. equi pneumonia, which may prompt appropriate treatment while awaiting confirmatory diagnostic tests results, such as bacterial culture and polymerase chain reaction. ${ }^{38}$

\section{Serology}

Although several serological assays have been developed to detect the presence of anti- $R$. equi antibodies, none can be recommended for use in the diagnosis of the disease. A positive result on a serologic assay cannot be used to differentiate among active infection, subclinical infection, exposure without infection, or maternal transfer of antibodies, and as such, use of these tests as either a diagnostic tool or as a screening tool (see following) is not justified. ${ }^{1,13,50}$

\section{Treatment}

Treatment with a macrolide antimicrobial in combination with rifampin is the recommended therapy for infection caused by $R$. equi ${ }^{1}$ (Table 1). Duration of treatment is dependent on the severity of the disease at the time of diagnosis but is typically weeks to months. ${ }^{12,37,42,51}$ Although a wide range of antimicrobials is reported to have in vitro efficacy against $R$. equi, their in vivo efficacy is limited, likely because of their limited ability to establish effective intracellular concentrations. ${ }^{12,45}$ The introduction of a combination of erythromycin and rifampin for $R$. equi treatment was first reported in the 1980s and was associated with an improvement in outcome based on historical survival data. ${ }^{12,51}$ Newer macrolides such as clarithromycin and azithromycin have more recently been used, primarily in an attempt to minimize the adverse effects reported after erythromycin use, and also to potentially improve treatment outcome. ${ }^{52,53}$ Adverse effects reported after erythromycin treatment include diarrhea (usually mild and self-limiting) and hyperthermia, and tachypnea in foals treated during hot weather. In one study, 26 (36\%) of 73 foals treated with erythromycin developed diarrhea, 18 developed hyperthermia (25\%), and $11(17 \%)$ developed respiratory distress. ${ }^{52}$ No difference in complication rates was reported in a retrospective study comparing combinations of rifampin with erythromycin, clarithromycin, or azithromycin, although a significantly better short- and long-term outcome was

Table I Recommended antimicrobial regimes for the treatment of Rhodococcus equi in foals

\begin{tabular}{lll}
\hline Drug & Dose $(\mathbf{m g} / \mathbf{k g})$ & Frequency \\
Rifampin & 5 & $\mathrm{q} / 2 \mathrm{~h}$ \\
Erythromycin & 25 & $\mathrm{q} 6-8 \mathrm{~h}$ \\
Clarithromycin & 7.5 & $\mathrm{q} / 2 \mathrm{~h}$ \\
Azithromycin & 10 & $\mathrm{q} 24-48 \mathrm{~h}$ \\
\hline
\end{tabular}

Abbreviation: h, hours. 
reported for clarithromycin and rifampin treatment. ${ }^{53}$ The requirement for less frequent dosing with either azithromycin (once a day) or clarithromycin (twice a day) when compared with erythromycin has also led to these drugs now being more commonly administered in cases of $R$. equi infection. ${ }^{1}$ Tulathromycin is a long-acting macrolide antimicrobial that has been investigated for treatment of $R$. equi infections, as its ability to provide sustained therapeutic concentrations could result in less-frequent treatment of affected foals. ${ }^{3,4}$ No significant differences among standard treatment, placebo, or treatment with tularithromycin was observed in two studies comparing treatment regimes in foals with ultrasonographically identified abscesses. ${ }^{3,4}$

The combination of rifampin and a macrolide is synergistic both in vitro and in vivo, and the use of the 2 drug classes as a combination decreases the chances of $R$. equi resistance to either drug. ${ }^{54-56}$ When used as monotherapy, resistance to rifampin develops quickly, as chromosomal mutation develops rapidly in most bacteria exposed to rifampin. ${ }^{56,57}$ Isolates resistant to rifampin have tended to exhibit high-level resistance, which suggests that this resistance develops in a single-step event and supports the use of rifampin in combination with other antimicrobials. Despite this, rifampin-resistant isolates have been isolated from foals treated with combination therapy. ${ }^{8,42,56}$ A recent study suggested that when both clarithromycin and rifampin are administered at the same time, the bioavailability of clarithromycin decreases significantly. ${ }^{58}$ This effect was believed to be associated with induction of intestinal efflux transporters and liver-metabolizing enzymes, resulting in less systemic absorption of clarithromycin. Despite this, the concentrations in epithelial lining fluid and bronchoalveolar lavage cells remained above the minimum inhibitory concentration (MIC) for the $R$. equi, and the clinical relevance of this effect remains to be determined. Although this treatment regime remains the mainstay of therapy for many clinicians, some have questioned whether, with this newer information, sole therapy with clarithromycin should be considered.

\section{Prevention}

Preventative measures aimed both at decreasing the risk of infection in foals, and at identifying foals early in the disease course, are widely used on farms with endemic infections in an attempt to decrease mortality and minimize the need for often long-term and expensive treatment.

\section{Hyperimmune plasma}

Administration of hyperimmune plasma (HIP) for prevention against $R$. equi pneumonia is a common practice on farms with endemic disease. ${ }^{1,59,60}$ Hyperimmune plasma is thought to confer protection primarily through the provision of $R$. equi-specific antibodies, but other constituents in plasma, such as fibronectin, complement components, collectins, cytokines, and acute-phase proteins, may also be involved. Intravenous administration of HIP has consistently proved effective in significantly reducing the severity of R. equi pneumonia in foals after experimental challenge. ${ }^{61-63}$ However, results of studies evaluating the efficacy of various HIP preparations under field conditions have given contradictory results. ${ }^{5,59,60,64}$ This suggests that various factors such as the method of immunizing plasma donors, the amount of HIP used, the timing of plasma administration, and management conditions, as well as the number of virulent bacteria in the environment, may influence the effectiveness of a particular HIP product.

In the recent American College of Veterinary Internal Medicine Consensus Statement, administration of plasma containing antibodies against $R$. equi was recommended as an aid in the prevention of infection on endemic farms, although the optimal dose and timing of administration remain unclear. ${ }^{1}$ Foals are believed to become infected within the first few days of life,,${ }^{11}$ and thus early administration of plasma, commonly no later than 2 days of age, is recommended. This passively acquired immunity is, however, likely to have waned to a nonprotective level within the period that foals are still susceptible to infection, and thus a second dose, administered at 2-4 weeks of age, is also commonly administered. ${ }^{11}$

\section{Vaccination}

Although there has been much interest in developing a vaccine capable of protecting foals against $R$. equi infection, to date, no effective vaccination strategy has been identified. Vaccination of mares during pregnancy with a vaccine containing proteins from a VapA containing $R$. equi strain has been shown to result in anti-R. equi antibody production in mares, transfer of antibody in colostrum to foals, and an increased opsonic antibody activity in foals. ${ }^{65}$ Significantly fewer foals in the vaccinated group (0/32) compared with in the control group $(4 / 15 ; P=0.02)$ developed $R$. equi pneumonia. As with HIP, vaccination of mares and subsequent passive transfer of antibodies is unlikely to provide full protection against $R$. equi infection because of the importance of cell-mediated immunity in protection against the disease. As such, vaccination of foals to stimulate this type of immunity is more likely to be a successful preventative strategy. However, the vaccine would need to be administered very 
early in life and be effective rapidly to be protective at the time when foals are believed to become infected. Vaccination at this time is complicated by the interference of maternal antibodies and the relative immaturity of the foal's immune system. Oral immunization with a live virulent $R$. equi was shown to be protective in foals after experimental challenge in one study. ${ }^{66}$ Foals were immunized at 2 days, 1 week, and 3 weeks of age via nasogastric administration of either $R$. equi or a placebo, and were then challenged by intrabronchial administration of bacteria at 3 weeks of age. Foals in the control group $(n=4)$ developed clinical signs of pneumonia by 9 days postchallenge, whereas those in the immunized group did not. Postmortem examinations performed 2 weeks after challenge also supported the production of a protective response in immunized foals, with control foals all developing extensive pyogranulomatous pulmonary consolidation, whereas the lungs of immunized foals were free of lesions. Although the results of this study appear promising, the efficacy of this protocol under field conditions has not been tested, and the effect of oral administration of virulent bacteria on environmental bacterial load should be considered.

\section{Environmental management}

$R$. equi is a saprophyte that persists and replicates in soil. It is ingested by grazing horses, survives passage through the gastrointestinal tract, and is then excreted in feces. Its ubiquitous nature on equine breeding farms can be explained by its enhanced growth in horse feces and its use of the volatile fatty acids present in the feces. ${ }^{67,68}$ Mares excrete bacteria within the feces, which can then be ingested by foals. In one study, $R$. equi could be isolated from the feces of $100 \%$ of foals by 4 weeks of age ${ }^{69}$ Bacterial replication in the soil is enhanced in particular types of soils ( $\mathrm{pH} 7.0-8.5)$ and at higher environmental temperatures. ${ }^{67}$ Aerosolization of virulent soil R. equi, favored by high soil concentrations and dry, dusty conditions, is considered to be the major mechanism of pulmonary infection. ${ }^{37}$ Preventative strategies targeted at minimizing environmental bacterial load, and thus aerosolization and inhalation, have been investigated. Increased stocking density, an increased number of mares and foals on a premises, and increased numbers of transient mares and foals have been identified as risk factors for the development of $R$. equi pneumonia in foals. ${ }^{6,770}$ Strong evidence for a decrease in the number of cases of pneumonia after modification of risk factors is lacking, although minimizing housing foals in bare, dusty paddocks, lanes, or holding pens and reducing stocking rates would seem to be a logical method of minimizing foal exposure to the organism. ${ }^{7}$ In a recent study, concentrations of virulent $R$. equi in air samples from stalls housing foals that developed $R$. equi pneumonia were significantly higher than those in samples from stalls housing foals that did not develop pneumonia, suggesting that attempts to minimize concentrations of airborne virulent R. equi may be beneficial. ${ }^{71}$

Isolation of clinically affected foals in an attempt to minimize environmental contamination and thus exposure of noninfected foals to virulent $R$. equi has been advocated as a preventative measure. ${ }^{72}$ Concentrations of virulent $R$. equi in the breathing zone of foals with $R$. equi pneumonia have not, however, been shown to be significantly higher than foals without disease, suggesting that affected foals do not pose an increased risk for direct aerosol transmission. ${ }^{73,74}$ Foals are known to have increased concentrations of virulent $R$. equi in their feces compared to adult horses, ${ }^{75}$ and in one small study, infected foals had higher concentrations of $R$. equi in fecal samples compared with nonaffected foals. ${ }^{76}$ Environmental contamination may be thus be diminished if affected foals are prevented from being housed in paddocks where nonaffected mares and foals may be grazed.

\section{Chemoprophylaxis}

\section{Gallium}

Gallium is a trivalent semimetal that is chemically similar to ferric iron and has been used as an aid in the management of infections caused by iron-dependent bacteria. ${ }^{77}$ Although sequestration of ferric iron by host proteins such as transferrin, lactoferrin, and ferritin is an innate defense mechanism aimed at minimizing bacterial survival by limiting access to iron, $R$. equi has the ability to acquire and use iron bound to both transferrin and lactoferrin, thus neutralizing this defence mechanism. ${ }^{78}$ When gallium is present, bacteria acquire it instead of iron from the host iron-binding proteins, and it is then incorporated into the bacterial metabolic pathways and enzymes that require iron. Because many of these enzymes are critical for cell functions such as DNA synthesis, the incorporation of gallium, which cannot be reduced from its trivalent form to the divalent form (as would occur with iron), results in cell death resulting from the inhibition of DNA synthesis and bacterial replication. ${ }^{77,79}$ Use of gallium for chemoprophylaxis has been reported to be an effective strategy in the management of a variety of bacterial diseases, and has been shown to have antimicrobial activity against $R$. equi in vitro. ${ }^{79,80}$ Gallium, as gallium maltolate, can be administered safely to foals via the oral route and has been shown to reach concentrations sufficient to suppress growth or kill $R$. equi in macrophages at a dose of $20-30 \mathrm{mg} / \mathrm{kg} .{ }^{80-83}$ 
However, a controlled, randomized, double-blinded clinical trial performed on breeding farms with a history of endemic $R$. equi infection showed no significant difference in the rate of clinically apparent $R$. equi pneumonia between foals treated with gallium maltolate $(30 \mathrm{mg} / \mathrm{kg}$ by mouth every 24 hours for the first 2 weeks of life) compared with foals treated with a placebo. ${ }^{13} \mathrm{~A}$ recent study investigated the utility of peripartum treatment of mares with gallium on decreasing fecal and airborne concentrations of virulent $R$. equi, which would thereby decrease environmental contamination. ${ }^{84}$ Fecal shedding of $R$. equi was significantly lower in mares treated with gallium, but this was not reflected in lower airborne concentrations.

\section{Antimicrobials}

Mass antimicrobial prophylaxis of all foals on endemically affected farms has been suggested as a method of preventing the development of pneumonia. Although in one study a significantly lower proportion of foals treated with azithromycin (every other day for the first 2 weeks of life) developed pneumonia compared with those not treated ( $5.3 \%$ versus $20.8 \%$ ), this method of prophylaxis is not recommended because of the high chance of the development of antimicrobial resistance. ${ }^{1,85}$ Although resistant isolates were not reported in this study, a subsequent report from a farm using treatment of foals who were subclinically affected identified widespread macrolide and rifampin resistance in $R$. equi isolates, which increased from a rate of $25 \%$ before treatment to $62 \%$ after treatment. ${ }^{9}$ Two recent studies have also questioned the efficacy and need for mass antimicrobial prophylaxis in subclinically affected foals on farms with endemic $R$. equi. ${ }^{3,4}$ In these studies, foals were screened on a weekly basis using clinical examinations and white cell counts, and abnormalities detected on these, including a rectal temperature of greater than $39.5^{\circ} \mathrm{C}$, respiratory rate greater than 80 /minute, abnormal thoracic auscultation, or an abnormally high white cell count, prompted thoracic ultrasonographic evaluation. Foals with an abscess score between $1-10 \mathrm{~cm}$ in one study, or between $5-10 \mathrm{~cm}$ in the second study, were randomly assigned to either treatment groups (various antimicrobial regimes including tularithromycin, rifampin and azithromycin, azithromycin alone, doxycycline, and doxycycline with rifampin) or a placebo on a blinded basis. Foals were subsequently monitored weekly until lesion resolution. Deterioration in clinical or ultrasonographic findings prompted a change in treatment to azithromycin and rifampin. There was no significant difference between groups in the proportion of foals that responded to the initial treatment, the duration of treatment, the proportion of foals that required a change of treatment, or the number of days until this treatment change was required. These results suggest that a high proportion (up to $88 \%$ ) of foals with subclinical $R$. equi infections can recover without antimicrobial treatment, and that treatment with antimicrobials does not appear to alter the proportion of those that resolve. ${ }^{3,4}$

\section{Screening}

Because of the potentially devastating outcome in foals infected with $R$. equi, and because in many cases the disease is well advanced by the time clinical signs become apparent, identification of foals with subclinical infections has become standard practice on many farms with endemic infections. Although screening for early identification of $R$. equi pneumonia is recommended, the best method to achieve this has yet to be identified. ${ }^{1}$ Because most $R$. equi infections are believed to occur within the first week or two of life, screening beginning at 3-4 weeks of age tends to be implemented, regardless of the method used. Screening methods evaluated have included visual inspection of foals, clinical examinations by farm personnel/veterinarians, hematologic parameters, serology, and thoracic imaging with either radiography or ultrasonography. Evaluation of serum antibody levels, fibrinogen, and serum amyloid A concentrations are considered ineffective screening tools, whereas clinical examinations, white cell count, and thoracic imaging (ultrasound) may allow for early identification of subclinically infected foals. ${ }^{10,14,86}$

In a population of 162 foals on a farm with a history of R. equi infections, measurement of fibrinogen concentration, white blood cell concentration, and anti- $R$. equi antibodies via an agar gel immunodiffusion assay (AGID) at 4-weekly intervals was investigated as a means of early identification of foals with $R$. equi pneumonia. ${ }^{14}$ Although both fibrinogen concentration and positive serology had poor sensitivity and specificity, the authors suggest that monitoring white cell concentration may be a useful approach for the early detection of $R$. equi pneumonia. In this study, a white cell count greater than $15,000 / \mu \mathrm{L}$ had a relatively good sensitivity $(78.6 \%)$ and specificity $(90.8 \%)$. In contrast, a more recent study ${ }^{10}$ in which white cell count, neutrophil count, and fibrinogen concentrations were evaluated in foals at 2-weekly intervals, hematologic screening had limited ability to predict foals that subsequently developed clinical signs of pneumonia.

In recent years, ultrasonographic screening of all foals on endemic farms at regular intervals has been employed in an attempt to detect evidence of pneumonia before clinical 
signs develop. Ultrasonographic abnormalities have been identified in $80 \%-93 \%$ of foals in recent studies performed on endemic farms ${ }^{3,4,10}$ although the percentage of foals with lesions that go on to develop clinical signs of pneumonia is considerably lower. Chaffin reported that only $21 \%$ (46/216) of foals that had ultrasonographically detectable lesions went on to develop pneumonia. ${ }^{10} \mathrm{~A}$ similarly high rate of apparent spontaneous resolution has been reported in Europe, suggesting that although ultrasound is a useful tool in detecting foals that may be subclinically infected with $R$. equi, the majority of these foals appear to be able to resolve the infection without treatment, and that identification of lesions should not be used as the sole reason to initiate therapy., ${ }^{3,4}$ Indeed, in a controlled study, there was no difference in the rate of recovery of foals with ultrasonographically identified pulmonary lesions between those that were administered a placebo and those that were treated with antimicrobials. ${ }^{3}$ Several grading systems have been developed in an attempt to quantify the severity of ultrasonographically visible lesions, and thus determine which foals may need to be treated and which ones will be able to resolve the infection without treatment. ${ }^{3,4,87}$ Despite these grading systems, it remains unclear which foals require treatment. It could be argued that because of the morbidity and mortality associated with clinical $R$. equi infections, treatment of foals subclinically affected should be implemented. However, the effect of mass antimicrobial therapy on rates of antimicrobial resistance, the cost associated with treatment, the risk of adverse reactions to the antimicrobials administered, and the evidence that many foals with subclinical pulmonary lesions recover without treatment should be considered before treatment protocols for these foals are implemented. It is likely that screening programs and the response to detection of a "positive" case will need to be adapted to individual farms and will vary depending on the historic morbidity and mortality, the finances and resources available, and the ability to alter practices depending on the results of the screening program.

\section{Prognosis}

The prognosis for foals with $R$. equi pneumonia varies depending on the origin of the foals (referral hospital versus farm study). Survival rates of $48 \%-82 \%$ in foals with pneumonia treated at a referral hospital have been reported. ${ }^{12,41,46,53,88}$ Foals in which an EPD is present were reported to have a poorer prognosis (43\% survival) compared with those without ( $82 \%$ survival). ${ }^{41}$ Survival rates of foals subclinically affected with $R$. equi (as assessed by thoracic ultrasonographic abnormalities) are very high, with close to $100 \%$ of foals recovering even without treatment. ${ }^{3,4}$

The prognosis for athletic function in foals that recover from pneumonia is also excellent. In one study, although only $54 \%(45 / 83)$ of foals that survived $R$. equi pneumonia went on to race compared with $65 \%$ of unaffected foals born in the same year, their performance was not different from that of the US racing population. ${ }^{88}$ Pulmonary function also appears to be normal in foals that recover from $R$. equi pneumonia. In a small study of seven 3-year-old horses with a history of $R$. equi pneumonia as foals, gas exchange during intense treadmill exercise was not compromised. ${ }^{89}$

\section{Summary}

Management of Rhodococcus equi infections in foals remains challenging, both for treatment of individual foals and for implementing effective and evidence-based preventative strategies. New evidence suggests that although many foals on endemically affected farms become infected, the majority appear to resolve the infection without treatment, highlighting the challenge of identifying effective preventative measures.

\section{Disclosure}

The author reports no conflicts of interest in this work.

\section{References}

1. Giguère $\mathrm{S}$, Cohen ND, Chaffin $\mathrm{MK}$, et al. Rhodococcus equi: clinical manifestations, virulence, and immunity. J Vet Intern Med. 2011;25(6):1221-1230.

2. Giguère S, Cohen ND, Chaffin MK, et al. Diagnosis, treatment, control, and prevention of infections caused by Rhodococcus equi in foals. $J$ Vet Intern Med. 2011;25(6):1209-1220.

3. Venner M, Astheimer K, Lämmer M, Giguère S. Efficacy of mass antimicrobial treatment of foals with subclinical pulmonary abscesses associated with Rhodococcus equi. J Vet Intern Med. 2013;27(1):171-176.

4. Venner M, Rödiger A, Laemmer M, Giguère S. Failure of antimicrobial therapy to accelerate spontaneous healing of subclinical pulmonary abscesses on a farm with endemic infections caused by Rhodococcus equi. Vet J. 2012;192(3):293-298.

5. Higuchi T, Arakawa T, Hashikura S, Inui T, Senba H, Takai S. Effect of prophylactic administration of hyperimmune plasma to prevent Rhodococcus equi infection on foals from endemically affected farms. Zentralbl Veterinarmed B. 1999;46(9):641-648.

6. Chaffin MK, Cohen ND, Martens RJ. Evaluation of equine breeding farm characteristics as risk factors for development of Rhodococcus equi pneumonia in foals. J Am Vet Med Assoc. 2003;222(4):467-475.

7. Muscatello G, Anderson GA, Gilkerson JR, Browning GF. Associations between the ecology of virulent Rhodococcus equi and the epidemiology of R. equi pneumonia on Australian thoroughbred farms. Appl Environ Microbiol. 2006;72(9):6152-6160.

8. Giguère $\mathrm{S}, \mathrm{Lee} \mathrm{E}$, Williams E, et al. Determination of the prevalence of antimicrobial resistance to macrolide antimicrobials or rifampin in Rhodococcus equi isolates and treatment outcome in foals infected with antimicrobialresistant isolates of R equi. J Am Vet Med Assoc. 2010;237(1):74-81. 
9. Burton AJ, Giguère S, Sturgill TL, et al. Macrolide- and rifampin-resistant Rhodococcus equi on a horse breeding farm, Kentucky, USA. Emerg Infect Dis. 2013;19(2):282-285.

10. Chaffin MK, Cohen ND, Blodgett GP, Syndergaard M. Do hematologic and ultrasonographic screening methods predict clinically apparent Rhodococcus equi in foals? Proceedings of the American College of Veterinary Internal Medicine Annual Forum; June 13-15, 2013; Seattle, WA.

11. Horowitz ML, Cohen ND, Takai S, et al. Application of Sartwell's model (lognormal distribution of incubation periods) to age at onset and age at death of foals with Rhodococcus equi pneumonia as evidence of perinatal infection. J Vet Intern Med. 2001;15(3):171-175.

12. Sweeney CR, Sweeney RW, Divers TJ. Rhodococcus equi pneumonia in 48 foals: response to antimicrobial therapy. Vet Microbiol. 1987;14(3):329-336.

13. Chaffin MK, Cohen ND, Martens RJ, O’Conor M, Bernstein LR. Evaluation of the efficacy of gallium maltolate for chemoprophylaxis against pneumonia caused by Rhodococcus equi infection in foals. Am JVet Res. 2011;72(7):945-957.

14. Giguère S, Hernandez J, Gaskin J, Miller C, Bowman JL. Evaluation of white blood cell concentration, plasma fibrinogen concentration, and an agar gel immunodiffusion test for early identification of foals with Rhodococcus equi pneumonia. J Am Vet Med Assoc. 2003;222(6) 775-781.

15. Hondalus MK, Diamond MS, Rosenthal LA, Springer TA, Mosser DM. The intracellular bacterium Rhodococcus equi requires Mac-1 to bind to mammalian cells. Infect Immun. 1993;61(7):2919-29129.

16. Hondalus MK, Mosser DM. Survival and replication of Rhodococcus equi in macrophages. Infect Immun. 1994;62(10):4167-4175.

17. Zink MC, Yager JA, Prescott JF, Fernando MA. Electron microscopic investigation of intracellular events after ingestion of Rhodococcus equi by foal alveolar macrophages. Vet Microbiol. 1987;14(3): 295-305.

18. Darrah PA, Hondalus MK, Chen Q, Ischiropoulos H, Mosser DM. Cooperation between reactive oxygen and nitrogen intermediates in killing of Rhodococcus equi by activated macrophages. Infect Immun. 2000;68(6):3587-3593.

19. Toyooka K, Takai S, Kirikae T. Rhodococcus equi can survive a phagolysosomal environment in macrophages by suppressing acidification of the phagolysosome. J Med Microbiol. 2005;54(Pt 11): 1007-1015.

20. Giguère S, Hondalus MK, Yager JA, Darrah P, Mosser DM, Prescott JF. Role of the 85-kilobase plasmid and plasmid-encoded virulence-associated protein A in intracellular survival and virulence of Rhodococcus equi. Infect Immun. 1999;67(7):3548-3557.

21. von Bargen K, Polidori M, Becken U, Huth G, Prescott JF, Haas A. Rhodococcus equi virulence-associated protein $\mathrm{A}$ is required for diversion of phagosome biogenesis but not for cytotoxicity. Infect Immun. 2009;77(12):5676-5681

22. Byrne BA. Virulence factors of Rhodococcus equi. Proceedings of the 18th American College of Veterinary Internal Medicine Annual Meeting; May 25-28, 2000; Seattle, WA.

23. Nordmann P, Ronco E, Nauciel C. Role of T-lymphocyte subsets in Rhodococcus equi infection. Infect Immun. 1992;60(7):2748-2752.

24. Kanaly ST, Hines SA, Palmer GH. Failure of pulmonary clearance of Rhodococcus equi infection in CD4+ T-lymphocyte-deficient transgenic mice. Infect Immun. 1993;61(11):4929-4932.

25. Kanaly ST, Hines SA, Palmer GH. Cytokine modulation alters pulmonary clearance of Rhodococcus equi and development of granulomatous pneumonia. Infect Immun. 1995;63(8):3037-3041.

26. Kanaly ST, Hines SA, Palmer GH. Transfer of a CD4+ Th1 cell line to nude mice effects clearance of Rhodococcus equi from the lung. Infect Immun. 1996;64(4):1126-1132.

27. Patton KM, McGuire TC, Hines MT, Mealey RH, Hines SA. Rhodococcus equi-specific cytotoxic T lymphocytes in immune horses and development in asymptomatic foals. Infect Immun. 2005;73(4):2083-2093.
28. Hines MT, Paasch KM, Alperin DC, Palmer GH, Westhoff NC, Hines SA. Immunity to Rhodococcus equi: antigen-specific recall responses in the lungs of adult horses. Vet Immunol Immunopathol. 2001;79(1-2):101-114.

29. Hines SA, Stone DM, Hines MT, et al. Clearance of virulent but not avirulent Rhodococcus equi from the lungs of adult horses is associated with intracytoplasmic gamma interferon production by CD4+ and CD8+ T lymphocytes. Clin Diagn Lab Immunol. 2003;10(2):208-215.

30. Hooper-McGrevy KE, Wilkie BN, Prescott JF. Immunoglobulin G subisotype responses of pneumonic and healthy, exposed foals and adult horses to Rhodococcus equi virulence-associated proteins. Clin Diagn Lab Immunol. 2003;10(3):345-351.

31. Patton KM, McGuire TC, Fraser DG, Hines SA. Rhodococcus equiinfected macrophages are recognized and killed by CD8+T lymphocytes in a major histocompatibility complex class I-unrestricted fashion. Infect Immun. 2004;72(12):7073-7083.

32. Lopez AM, Hines MT, Palmer GH, Alperin DC, Hines SA. Identification of pulmonary T-lymphocyte and serum antibody isotype responses associated with protection against Rhodococcus equi. Clin Diagn Lab Immunol. 2002;9(6):1270-1276.

33. Hietala SK, Ardans AA. Interaction of Rhodococcus equi with phagocytic cells from R. equi-exposed and non-exposed foals. Vet Microbiol. 1987;14(3):307-320.

34. Breathnach CC, Sturgill-Wright T, Stiltner JL, Adams AA, Lunn DP, Horohov DW. Foals are interferon gamma-deficient at birth. Vet Immunol Immunopathol. 2006;112(3-4):199-209.

35. Jacks S, Giguère S, Crawford PC, Castleman WL. Experimental infection of neonatal foals with Rhodococcus equi triggers adult-like gamma interferon induction. Clin Vaccine Immunol. 2007;14(6):669-677.

36. Harris SP, Hines MT, Mealey RH, Alperin DC, Hines SA. Early development of cytotoxic $\mathrm{T}$ lymphocytes in neonatal foals following oral inoculation with Rhodococcus equi. Vet Immunol Immunopathol. 2011;141(3-4):312-316.

37. Giguère S, Prescott JF. Clinical manifestations, diagnosis, treatment, and prevention of Rhodococcus equi infections in foals. Vet Microbiol. 1997;56(3-4):313-334.

38. Leclere M, Magdesian KG, Kass PH, Pusterla N, Rhodes DM. Comparison of the clinical, microbiological, radiological and haematological features of foals with pneumonia caused by Rhodococcus equi and other bacteria. Vet J. 2011;187(1):109-112.

39. Dunkel B, Dolente B, Boston RC. Acute lung injury/acute respiratory distress syndrome in 15 foals. Equine Vet J. 2005;37(5):435-440.

40. Lakritz J, Wilson WD, Berry CR, Schrenzel MD, Carlson GP, Madigan JE. Bronchointerstitial pneumonia and respiratory distress in young horses: clinical, clinicopathologic, radiographic, and pathological findings in 23 cases (1984-1989). JVet Intern Med. 1993;7(5): $277-288$.

41. Reuss SM, Chaffin MK, Cohen ND. Extrapulmonary disorders associated with Rhodococcus equi infection in foals: 150 cases (1987-2007). J Am Vet Med Assoc. 2009;235(7):855-863.

42. Johns IC, Desrochers A, Wotman KL, Sweeney RW. Presumed immunemediated hemolytic anemia in two foals with Rhodococcus equi infection. J Vet Emerg Crit Care (San Antonio). 2011;21(3):273-278.

43. Mair TS. Bacterial pneumonia associated with corticosteroid therapy in three horses. Vet Rec. 1996;138(9):205-207.

44. Schmaldienst S, Horl WH. Bacterial infections during immunosuppression - immunosuppressive agents interfere not only with immune response, but also with polymorphonuclear cell function. Nephrol Dial Transplant. 1996;11(7):1243-1245.

45. Jacks SS, Giguère S, Nguyen A. In vitro susceptibilities of Rhodococcus equi and other common equine pathogens to azithromycin, clarithromycin, and 20 other antimicrobials. Antimicrob Agents Chemother. 2003;47(5):1742-1745.

46. Giguère S, Jordan LM, Glass K, Cohen ND. Relationship of mixed bacterial infection to prognosis in foals with pneumonia caused by Rhodococcus equi. J Vet Intern Med. 2012;26(6):1443-1448. 
47. Sellon DC, Besser TE, Vivrette SL, McConnico RS. Comparison of nucleic acid amplification, serology, and microbiologic culture for diagnosis of Rhodococcus equi pneumonia in foals. J Clin Microbiol. 2001;39(4):1289-1293.

48. Ramirez S, Lester GD, Roberts GR. Diagnostic contribution of thoracic ultrasonography in 17 foals with Rhodococcus equi pneumonia. Vet Radiol Ultrasound. 2004;45(2):172-176.

49. Giguère $S$, Roberts GD. Association between radiographic pattern and outcome in foals with pneumonia caused by Rhodococcus equi. Vet Radiol Ultrasound. 2012;53(6):601-604.

50. Martens RJ, Cohen ND, Chaffin MK, et al. Evaluation of 5 serologic assays to detect Rhodococcus equi pneumonia in foals. $\mathrm{J} \mathrm{Am} \mathrm{Vet} \mathrm{Med}$ Assoc. 2002;221(6):825-833.

51. Hillidge CJ. Use of erythromycin-rifampin combination in treatment of Rhodococcus equi pneumonia. Vet Microbiol. 1987;14(3): $337-342$.

52. Stratton-Phelps M, Wilson WD, Gardner IA. Risk of adverse effects in pneumonic foals treated with erythromycin versus other antibiotics: 143 cases (1986-1996). J Am Vet Med Assoc. 2000;217(1):68-73.

53. Giguère S, Jacks S, Roberts GD, Hernandez J, Long MT, Ellis C. Retrospective comparison of azithromycin, clarithromycin, and erythromycin for the treatment of foals with Rhodococcus equi pneumonia. J Vet Intern Med. 2004;18(4):568-573.

54. Nordmann P, Ronco E. In-vitro antimicrobial susceptibility of Rhodococcus equi. J Antimicrob Chemother. 1992;29(4):383-393.

55. Prescott JF, Nicholson VM. The effects of combinations of selected antibiotics on the growth of Corynebacterium equi. $J$ Vet Pharmacol Ther. 1984;7(1):61-64.

56. Fines M, Pronost S, Maillard K, Taouji S, Leclercq R. Characterization of mutations in the rpoB gene associated with rifampin resistance in Rhodococcus equi isolated from foals. J Clin Microbiol. 2001;39(8): 2784-2787.

57. Dowling PM. Antimicrobial therapy. In: Bertone JJ, Horspool LJI, editors. Equine Clinical Pharmacology. Philadelphia, PA: Elsevier Limited; 2004:13-49.

58. Peters J, Block W, Oswald S, Freyer J, et al. Oral absorption of clarithromycin is nearly abolished by chronic comedication of rifampicin in foals. Drug Metab Dispos. 2011;39(9):1643-1649.

59. Madigan JE, Hietala S, Muller N. Protection against naturally acquired Rhodococcus equi pneumonia in foals by administration of hyperimmune plasma. J Reprod Fertil Suppl. 1991;44:571-578.

60. Giguère S, Gaskin JM, Miller C, Bowman JL. Evaluation of a commercially available hyperimmune plasma product for prevention of naturally acquired pneumonia caused by Rhodococcus equi in foals. $J$ Am Vet Med Assoc. 2002;220(1):59-63.

61. Hooper-McGrevy KE, Giguere S, Wilkie BN, Prescott JF. Evaluation of equine immunoglobulin specific for Rhodococcus equi virulenceassociated proteins $\mathrm{A}$ and $\mathrm{C}$ for use in protecting foals against Rhodococcus equi-induced pneumonia. Am J Vet Res. 2001;62(8): $1307-1313$

62. Martens RJ, Martens JG, Fiske RA, Hietala SK. Rhodococcus equi foal pneumonia: protective effects of immune plasma in experimentally infected foals. Equine Vet J. 1989;21(4):249-255.

63. Prescott JF, Nicholson VM, Patterson MC, et al. Use of Rhodococcus equi virulence-associated protein for immunization of foals against R equi pneumonia. Am J Vet Res. 1997;58(4):356-359.

64. Hurley JR, Begg AP. Failure of hyperimmune plasma to prevent pneumonia caused by Rhodococcus equi in foals. Aust Vet J. 1995;72(11):418-420.

65. Cauchard J, Sevin C, Ballet JJ, Taouji S. Foal IgG and opsonizing anti-Rhodococcus equi antibodies after immunization of pregnant mares with a protective VapA candidate vaccine. Vet Microbiol. 2004;104(1-2):73-81.

66. Hooper-McGrevy KE, Wilkie BN, Prescott JF. Virulence-associated protein-specific serum immunoglobulin G-isotype expression in young foals protected against Rhodococcus equi pneumonia by oral immunization with virulent R. equi. Vaccine. 2005;23(50):5760-5767.
67. Hughes KL, Sulaiman I. The ecology of Rhodococcus equi and physicochemical influences on growth. Vet Microbiol. 1987;14(3): 241-250.

68. Barton MD, Hughes KL. Ecology of Rhodococcus equi. Vet Microbiol. 1984;9(1):65-76.

69. Takai S, Fujimori T, Katsuzaki K, Tsubaki S. Ecology of Rhodococcus equi in horses and their environment on horse-breeding farms. Vet Microbiol. 1987;14(3):233-239.

70. Cohen ND, O'Conor MS, Chaffin MK, Martens RJ. Farm characteristics and management practices associated with development of Rhodococcus equi pneumonia in foals. $J$ Am Vet Med Assoc. 2005;226(3):404-413.

71. Cohen ND, Chaffin MK, Kuskie KR, Syndergaard MK, Blodgett GP, Takai S. Association of perinatal exposure to airborne Rhodococcus equi with risk of pneumonia caused by $\mathrm{R}$ equi in foals. Am J Vet Res. 2013;74(1):102-109.

72. Giguère $\mathrm{S}$, Prescott JF. Strategies for the control of Rhodococcus equi infections on enzootic farms. Proceedings of the American Association of Equine Practitioners Annual Convention; December 7-10, 1997; Phoenix, AZ.

73. Chicken C, Muscatello G, Freestone J, Anderson GA, Browning GF, Gilkerson JR. Air sampling in the breathing zone of neonatal foals for prediction of subclinical Rhodococcus equi infection. Equine Vet $J$. 2012;44(2):203-206.

74. Muscatello G, Gilkerson JR, Browning GF. Detection of virulent Rhodococcus equi in exhaled air samples from naturally infected foals. J Clin Microbiol. 2009;47(3):734-737.

75. Takai S, Ohkura H, Watanabe Y, Tsubaki S. Quantitative aspects of fecal Rhodococcus (Corynebacterium) equi in foals. J Clin Microbiol. 1986;23(4):794-796.

76. Takai S, Iimori S, Tsubaki S. Quantitative fecal culture for early diagnosis of Corynebacterium (Rhodococcus) equi enteritis in foals. Can J Vet Res. 1986;50(4):479-484.

77. Bernstein LR. Mechanisms of therapeutic activity for gallium. Pharmacol Rev. 1998;50(4):665-682.

78. Jordan MC, Harrington JR, Cohen ND, et al. Effects of iron modulation on growth and viability of Rhodococcus equi and expression of virulence-associated protein A. Am J Vet Res. 2003;64(11):1337-1346.

79. Harrington JR, Martens RJ, Cohen ND, Bernstein LR. Antimicrobial activity of gallium against virulent Rhodococcus equiin vitro and in vivo. J Vet Pharmacol Ther. 2006;29(2):121-127.

80. Martens RJ, Miller NA, Cohen ND, et al. Chemoprophylactic antimicrobial activity of gallium maltolate against intracellular Rhodococcus equi. J Equine Vet Sci. 2007;27(8):341-345.

81. Martens RJ, Cohen ND, Fajt VR, et al. Gallium maltolate: safety in neonatal foals following multiple enteral administrations. $J$ Vet Pharmacol Ther. 2010;33(2):208-212.

82. Martens RJ, Mealey K, Cohen ND, et al. Pharmacokinetics of gallium maltolate after intragastric administration in neonatal foals. Am J Vet Res. 2007;68(10):1041-1044.

83. Chaffin MK, Fajt V, Martens RJ, et al. Pharmacokinetics of an orally administered methylcellulose formulation of gallium maltolate in neonatal foals. $J$ Vet Pharmacol Ther. 2010;33(4):376-382.

84. Buchanan B, Kuskie K, Pusterla N, Cohen N. Effect of gallium nitrate on fecal shedding of Rhodococcus equi in mares. Proceedings of the American College of Veterinary Internal Medicine Annual Forum; June 15-18, 2011; Denver, CO.

85. Chaffin MK, Cohen ND, Martens RJ. Chemoprophylactic effects of azithromycin against Rhodococcus equi-induced pneumonia among foals at equine breeding farms with endemic infections. $J$ Am Vet Med Assoc. 2008;232(7):1035-1047.

86. Cohen ND, Chaffin MK, Vandenplas ML, et al. Study of serum amyloid A concentrations as a means of achieving early diagnosis of Rhodococcus equi pneumonia. Equine Vet J. 2005;37(3):212-216.

87. Slovis NM, McCracken JL, Mundy G. How to use thoracic ultrasound to screen foals for Rhodococcus equi at affected farms. Proc Am Assoc Equine Practitioners Annual Conference. 2005;51:274-278. 
88. Ainsworth DM, Eicker SW, Yeagar AE, et al. Associations between physical examination, laboratory, and radiographic findings and outcome and subsequent racing performance of foals with Rhodococcus equi infection: 115 cases (1984-1992). J Am Vet Med Assoc. 1998;213(4):510-515.
89. Funkquist P, Demmers S, Hedenstierna G, Jensen Waern M, Nyman G. Gas exchange during intense exercise in Standardbreds with earlier Rhodococcus equi pneumonia. Equine Vet J Suppl. 2002;(34): 434-441.

\section{Publish your work in this journal}

Veterinary Medicine: Research and Reports is an international, peer-reviewed, open access journal publishing original research, case reports, editorials, reviews and commentaries on all areas of veterinary medicine. The manuscript management system is completely online and includes a very quick and fair peer-review system.

Submit your manuscript here: http://www.dovepress.com/veterinary-medicine-research-and-reports-journal
Visit http://www.dovepress.com/testimonials.php to read real quotes from published authors. 